\title{
The Synthesis and Characterisation of 2-methyl-N- ((4-methylpyridine-2-yl)carbamothiol)benzamide: Its Preparation with Antibacterial Study
}

\author{
Farook Adam, ${ }^{1 *}$ Nur Nadia Fatihah, ${ }^{1}$ Nadiah Ameram, ${ }^{1}$ \\ Sreeramanan Subramaniam ${ }^{2}$ and Safiah Ahmad Mubarrakh ${ }^{2}$ \\ ${ }^{1}$ School of Chemical Sciences, Universiti Sains Malaysia, \\ 11800 USM Pulau Pinang, Malaysia \\ ${ }^{2}$ School of Biological Sciences, Universiti Sains Malaysia, \\ 11800 USM Pulau Pinang, Malaysia \\ *Corresponding author: farook@usm.my
}

Published online: 25 August 2016

To cite this article: Adam, F. et al. (2016). The synthesis and characterisation of 2-methyl-N-((4methylpyridine-2-yl)carbamothiol)benzamide: Its preparation with antibacterial study. J. Phys. Sci., 27(2), 83-101, DOI: 10.21315/jps2016.27.2.7

To link to this article: http://dx.doi.org/10.21315/jps2016.27.2.7

\begin{abstract}
The compound, 2-methyl-N-((4-methylpyridin-2-yl)carbamothioyl)benzamide was derived from ortho-toluylchloride and 2-amino-4-picoline. It was fully crystallised and characterised on the basis of elemental analysis, X-ray crystallography and spectroscopic techniques namely infra-red, $U v$-Vis and nuclear magnetic resonance. The melting point was in the range of $164.9^{\circ} \mathrm{C}-165.8^{\circ} \mathrm{C}$. The Fourier transform infrared (FTIR) analysis shows the following vibrational frequencies for $v(N-H), v(C=O), v(C-N)$ and $v(C=S)$ at $3237 \mathrm{~cm}^{-1}, 1683 \mathrm{~cm}^{-1}, 1329 \mathrm{~cm}^{-1}$ and $1154 \mathrm{~cm}^{-1}$ respectively. ${ }^{1} \mathrm{H} \mathrm{NMR}$ results showed chemical shifts at $9.140 \mathrm{ppm}$ and 12.983 ppm for the two $\mathrm{N}$-H protons. Single crystal $X$-ray diffraction studies on the compound showed it to be a rigid molecule due to the presence of internal hydrogen bonding. The compound shows antibacterial activity towards gram positive and gram negative bacteria.
\end{abstract}

Keywords: Synthesis, thiourea moiety, anti-bacterial study, benzamide, diffraction studies

\section{INTRODUCTION}

For the past few decades, thiourea derivatives have attracted great attention as versatile ligands in numerous applications. ${ }^{1}$ This is due to its unique properties which enable it to coordinate with various transition metal ions as monodentate or bidentate ligands. ${ }^{2-5}$ Thiourea derivatives for instance obtained as substituted benzoylthiourea or phenylthiourea derivatives are attractive model compounds 
for studies in solid-state chemistry due to their tendency for the formation of intra- and intermolecular hydrogen bonds of the $\mathrm{N}-\mathrm{H}$ proton-donor groups to sulphur and carbonyl oxygen atoms. ${ }^{6,7}$ To date, these derivatives are widely used in numerous applications such as in pharmaceutical industry as potential therapeutic agents, antibacterial, ${ }^{8,9}$ anti-HIV,${ }^{10}$ anticancer drugs ${ }^{11}$ and antidepressants, ${ }^{12}$ as well as antihyperlipidemic, antiallergic, antiparasitic, platelet antiaggregating and antiproliferative activities. ${ }^{13}$ Previous studies have reported that the compounds containing thiourea moieties have been used extensively and commercially as herbicides, fungicides and insecticides agents in the agrochemical industries. ${ }^{14}$ The new para cleavage of $\mathrm{C}-\mathrm{Cl}$ bond of the benzoyl chloride by nitrogen atom of the bidentate thiocyanate produces carbonyl isothiocyanate. This mechanism is shown in Figure 1.

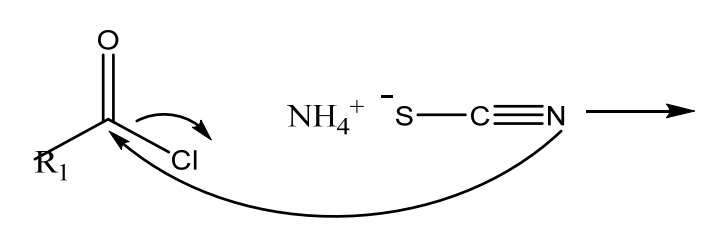<smiles>[R]C(=O)N=C=S</smiles><smiles>[R]C(=O)N1CCCCN([R2])[SH+]1</smiles><smiles>[R]NC(=S)NC([R])=O</smiles>

Figure 1: Mechanism of reaction of ammonium thiocyanate with benzoyl chloride forming thiourea benzamide derivatives.

Several studies have revealed that thiourea derivatives have not only been used in the medical and agriculture applications, but they also play a major contribution in the environmental and industrial applications. In the case of 1-benzoyl-3propylthiourea, it has been used as an effective adsorbent for removal of mercury ions from aqueous solutions. ${ }^{15}$ Additionally, thiourea and its derivatives can serve as useful host materials or inclusion compounds exhibiting a wide range of applications in the development of electronics and optoelectronics devices. ${ }^{16}$ Thiourea and its derivatives have also been found to be an effective agent of corrosion inhibitors because sulphur atom is easily protonated in acidic solution. $^{17}$

This communication focuses on the synthesis of a new compound from carbonyl thiourea. The chemical structure was confirmed by several spectroscopic methods namely IR, ${ }^{1} \mathrm{H}$ and ${ }^{13} \mathrm{C}$ NMR spectroscopy and single crystal X-ray diffraction structural analysis. The compound was tested for antimicrobial activity and toxicity. This paper in part addresses the world's concern with seeking new 
antimicrobial agents with maximum efficacy and low toxicity, especially strains resistant to current antibiotics.

\section{EXPERIMENTAL}

\subsection{Raw Materials}

Acetone (System, 99.5\%), ethyl alcohol (HmbG Chemical, 99.74\%), orthobenzoyl chloride (Merck, 99.5\%), ammonium thiocyanate (Merck, 99.5\%), 2amine-4-methylpyridine $\left(\mathrm{C}_{8} \mathrm{H}_{8} \mathrm{~N}_{2}\right.$; Merck, 99.5\%) and deuterium oxide (Aldrich, 99.9\%) were used as received. All other chemicals used were AR grade or of high purity and used directly without further purification.

\subsection{Physical Measurements}

All reactions were carried out under an ambient atmosphere and no special precautions were taken to exclude air or moisture during work-up. All chemicals were purchased from Sigma Aldrich or Merck and used as received without further purification. Infrared spectra of the synthesised compounds were recorded from $\mathrm{KBr}$ pellets using FTIR Perkin Elmer 100 Spectrophotometer in the spectral range of $4000-400 \mathrm{~cm}^{-1}$. The ${ }^{1} \mathrm{H}$ and ${ }^{13} \mathrm{C}$ NMR were recorded using Bruker Avance III $300 \mathrm{MHz}$ spectrometer in acetone- $\mathrm{d}_{6}$. Room temperature diffraction data for 2a was collected on a Bruker SMART APEX $4 \mathrm{~K} \mathrm{CCD} \mathrm{diffractometer}$ (Mo K a radiation, $\mathrm{k}=0.71073 \AA$ ). The structure was solved and refined by using SHELX suit. All nonhydrogen atoms were refined anisotropically. The perspective view of the molecule was obtained using ORTEP-32 for Windows. The crystallographic data was collected by SMART software, while cell refinement data was analysed by using SAINT software. Data reduction, structure, molecular graphic and value of hydrogen bonding were calculated by SHELXTL and PLATON.

\subsection{Preparation of 2-methyl-N-((4-methylpyridin-2-yl)carbamothioyl) benzamide}

Freshly prepared substituted $o$-benzoyl chloride $(2.0 \mathrm{~g}, 13 \mathrm{mmol})$ was added dropwise to a stirred acetone solution $(30 \mathrm{ml})$ of ammonium thiocyanate $(0.98 \mathrm{~g}$, $13 \mathrm{mmol}$ ). The mixture was stirred for $10 \mathrm{~min}$. A solution of 2-amino-4-picoline in acetone was added and the reaction mixture was refluxed for $3 \mathrm{~h}$, after which the solution was poured into a beaker containing some ice cubes. The resulting precipitate was collected by filtration, washed several times with a cold ethanol/water mixture followed by recrystallisation from methanol to afford the title compound as colourless single crystalline solids (2.65 g, 66\%). 


\subsection{Antibacterial Test}

\subsubsection{Preparation of samples, positive control and negative control}

The compounds were obtained after a few weeks of synthesis which is 2-methyl$\mathrm{N}$-((4-methylpyridin-2yl)carbamothioyl)benzamide. The crystal compounds were ground to obtain powdered form. The powdered form were then dissolved using $25 \%$ mixture of ethanol and methanol and then were used in the bacterial assay. The working stock concentrations for all the compounds were $15 \mathrm{mg} \mathrm{ml}^{-1}$. Chloramphenicol (+) at the concentration of $30 \mu \mathrm{g} \mathrm{ml}^{-1}$ was used as positive control in this study. Chloramphenicol (Sigma-Aldrich) was prepared by dissolving $0.3 \mathrm{mg}$ of Chloramphenicol into $0.3 \mathrm{ml}$ of $25 \%$ methanol. The negative control used is $25 \%$ methanol (-).

\subsubsection{Bacterial strains}

Four American Type Culture Collection (ATCC) pathogenic strains provided by School of Biological Sciences, Universiti Sains Malaysia were used in this study. The bacteria used for the antibacterial studies are Escherichia Coli ATCC 2592, Pseudomonas aeruginosa ATCC 2785, Bacillus subtilis (CDR) and Staphylococcus aureus ATCC 25923. Prior to be used in the bacterial assay, the bacteria were grown on both Mueller Hinton $(\mathrm{MH})$ broth and agar are placed in an incubator at $37^{\circ} \mathrm{C}$ and observed for confluency of its growth.

\subsubsection{Agar disc diffusion assay}

The disc diffusion (Kirby-Baurer) technique, based on the recommended standards of the National Committee for Clinical Laboratory Standards (NCCLS), was used for antibacterial test. An overnight suspension culture of the four bacterial strains was prepared on Mueler Hinton Agar (MHA) media by adding $100 \mu \mathrm{l}$ of the suspension culture onto the middle of the plate and spreading it evenly on the plate using L-rod. Sterile discs were prepared (diameter $=6 \mathrm{~mm}$ ) and placed on the culture spread agar media. The discs were impregnated with $20 \mu \mathrm{l}$ of the working stock of each of the compounds. Chloramphenicol $(+)$ was used as positive control to check the sensitivity of the strains. $25 \%$ of mixture of methanol and ethanol (-) was used as negative control. The inoculated plates were incubated at $37^{\circ} \mathrm{C}$ for $24 \mathrm{~h}$. The antibacterial activity was evaluated by measuring diameter of the inhibition zone around the disc. 


\subsubsection{Statistical analysis}

Each set of experiment were done in six replicates. Means in the experiment were analysed using uni-variate analysis of variance and differential with Duncan's test.

\section{RESULTS AND DISCUSSION}

2-methyl-N-((4-methylpyridin-2-yl)carbamothioyl)benzamide was synthesised in excellent yields following the method described by Douglass et al., ${ }^{18}$ which involved the reaction of ortho-toluylchloride with potassium thiocyanate in acetone followed by condensation of the resulting ortho-carbonyl isothiocyanate with the appropriate primary amine. All spectroscopic methods and elemental analyses confirmed the proposed structures of the new compound. The characteristic IR bands of the compound are shown in Figure 2.

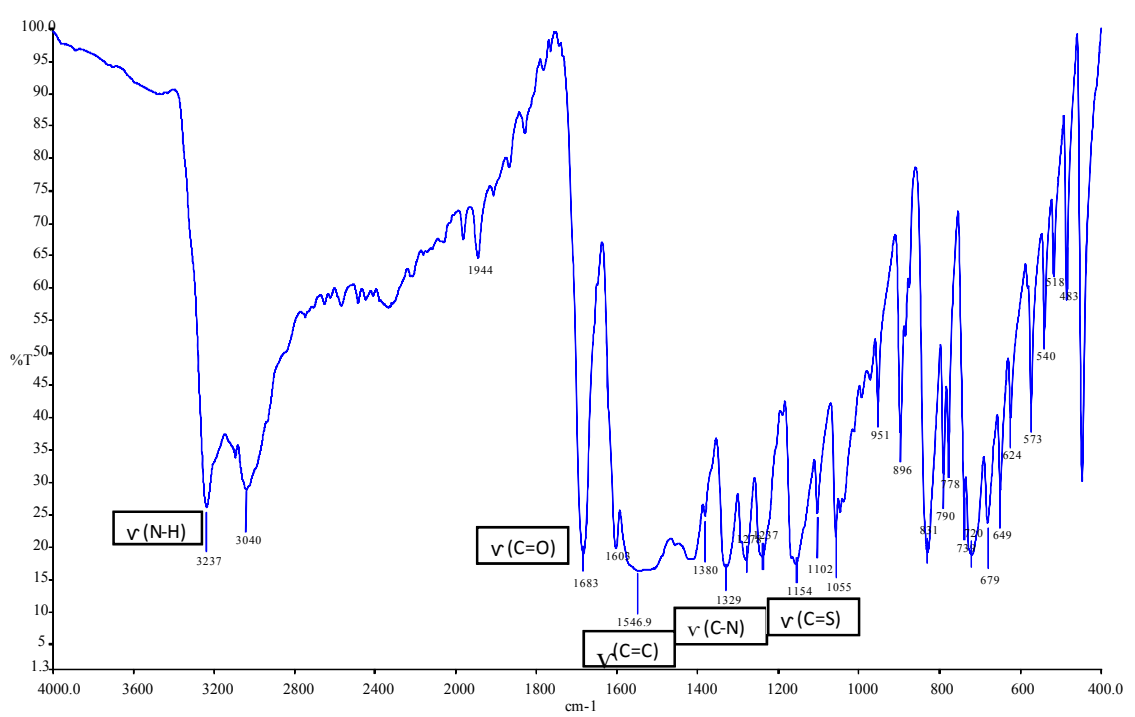

Figure 2: IR spectra for 2-methyl-N-((4-methylpyridin-2-yl)carbamothioyl)benzamide.

The compound showed two bands at $3433 \mathrm{~cm}^{-1}$ and $3233 \mathrm{~cm}^{-1}$ which was ascribed to the $\mathrm{N}-\mathrm{H}$ stretching vibrations. This difference between the $v \mathrm{NH}$ and $3237-3040 \mathrm{~cm}^{-1}$ stretching vibration frequencies was due to an intramolecular hydrogen bond (X-ray single-crystal diffraction data), where the carbonyl group was connected to the imine group. The band at $1683 \mathrm{~cm}^{-1}$ was due to the $\mathrm{C}=\mathrm{O}$ stretching vibration. The strong band at $1547 \mathrm{~cm}^{-1}$ was attributed to the $v \mathrm{C}=\mathrm{C}$ stretching vibration. The strong band at $1329 \mathrm{~cm}^{-1}$ was due to $v \mathrm{C}-\mathrm{N}$ stretching, 
whereas the band at $1154 \mathrm{~cm}^{-1}$ was due to the thiocarbonyl $(\mathrm{C}=\mathrm{S})$ group stretching vibration. The elemental analysis for this compound agrees with the expected structure of the molecules. However the percentages of $\mathrm{C}$ atom and $\mathrm{N}$ for the ligand are slightly larger than the theoretical value. The calculated and experimental (in bracket) values for the $\mathrm{CHN}$ analysis are as follows: $\mathrm{C}=58.95 \%$ (59.58\%), $\mathrm{H}=5.25 \%$ (5.28\%), $\mathrm{N}=14.72 \%$ (14.60\%).

Figure 3 shows the UV-Vis spectrum of 2-methyl-N-((4-methylpyridin-2yl)carbamothioyl)benzamide. The first sharp peak is due to the solvent methanol peaks, The carbonyl group in 2-methyl-N-((4-methylpyridin-2yl)carbamothioyl)benzamide undergo $n-\Pi^{*}$ and $\Pi-\Pi^{*}$ transitions appear at $\lambda, 280$ $\mathrm{nm}$ to $290 \mathrm{~nm} .{ }^{19}$ The UV-Vis spectrum of 2-methyl-N-((4-methylpyridin-2yl)carbamothioyl)benzamide showed the synthesised compounds have bands which represent carbonyl chromophores and thiol chromophores. The carbonyl peak was observed at $\lambda \max 277.4 \mathrm{~nm}$ with strong band. The weak bands (or shoulder) emitted by carbonyl chromophores were attributed to the highly conjugated system in the synthesised compounds. ${ }^{20}$ For the thiol chromophores of the synthesised compounds, the absorption observed at $\lambda \max 347.6 \mathrm{~nm}$ with strong adsorption band. The spectra appeared as broad absorption bands, because each electronic level is associated with multiple vibrational and rotational energy levels.

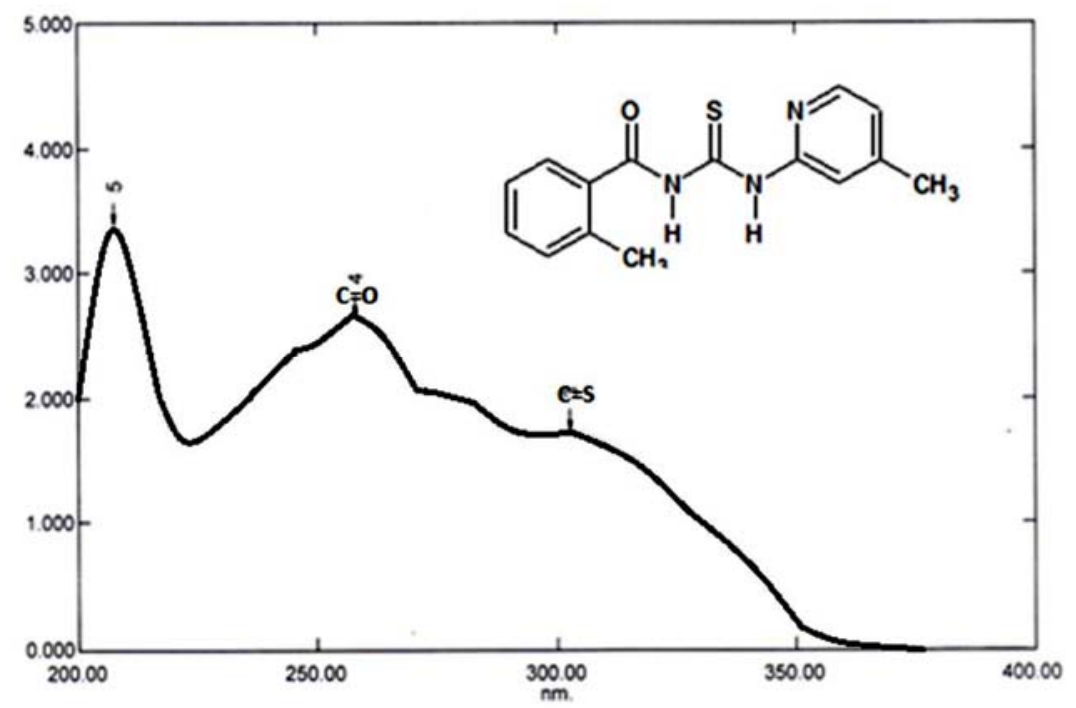

Figure 3: The Uv-vis spectrum of 2-methyl-N-((4-methylpyridin-2-yl)carbamothioyl) benzamide. 
Figure 4 shows the ${ }^{1} \mathrm{H}$ NMR spectrum of 2-methyl-N-((4-methylpyridin-2yl)carbamothioyl)benzamide. Dimethyl sulfoxide was used as the deuterated solvent at the chemical shift of $2.5 \mathrm{ppm}$. Corresponding to the literature, the ${ }^{1} \mathrm{HNMR}$ spectrum of 2-methyl-N-((4-methylpyridin-2-yl)carbamothioyl) benzamide indicates that the NH resonance appear at $13.16 \mathrm{ppm}$ and $11.64 \mathrm{ppm}$, but the resonance vary with different parameters, such as the substituted groups on the rings, which release and withdraw electron density in each ring, their positions and intra- and intermolecular hydrogen bonding.<smiles>Cc1ccccc1C(=O)NC(=S)Nc1ccccn1</smiles>

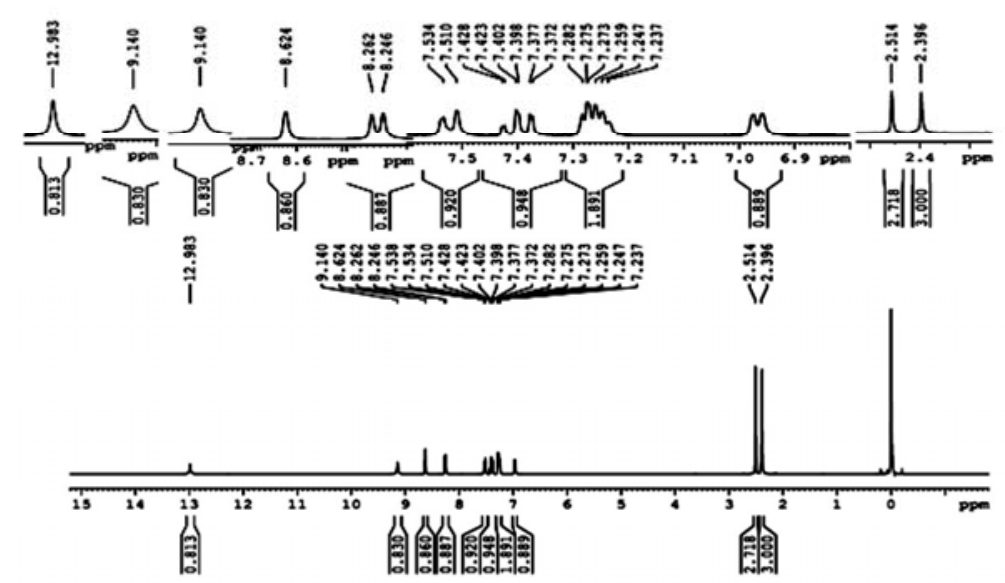

Figure 4: ${ }^{1} \mathrm{H}$ NMR for 2-methyl-N-((4-methylpyridin-2-yl)carbamothioyl) benzamide.

In most compounds with aromatic substituent at N1, the hydrogen bonded proton N1-H6 has a higher proton chemical shift, i.e., between 11 and $12 \mathrm{ppm} .{ }^{1} \mathrm{H}$ NMR studied in chloroform show that the proton of N1-H6 chemical shift was found at about $\delta 12.983 \mathrm{ppm}(\mathrm{s}, 1 \mathrm{H})$ for the hydrogen bonded proton N2-H6 appeared in downfield. The chemical shift of proton $(\mathrm{H} 7)$ is about $\delta 9.140 \mathrm{ppm}(\mathrm{s}, 1 \mathrm{H})$. The chemical shift of proton $\mathrm{H} 5, \delta=(2.514 \mathrm{ppm})($ singlet, $3 \mathrm{H})$ appeared downfield compared to proton $\mathrm{H} 9, \delta=(2.369 \mathrm{ppm})($ singlet, $3 \mathrm{H})$. The proton $\mathrm{H} 8$ was a singlet at $\delta=8.624 \mathrm{ppm}(1 \mathrm{H})$. The proton $\mathrm{H} 11$ and $\mathrm{H} 2$ were found at $\delta=7.534$ $7.510 \mathrm{ppm}(\mathrm{d}, 1 \mathrm{H})$ and $\delta=8.262-8.246 \mathrm{ppm}(\mathrm{d}, 1 \mathrm{H})$ respectively. Whereas the proton $\mathrm{H} 3$ and $\mathrm{H} 4$ appeared at $\delta=(7.282-7.237 \mathrm{ppm})$ (unequal multiplet, $2 \mathrm{H}$ ) respectively. While proton at $\mathrm{H} 1$ and $\mathrm{H} 10$ is at the chemical shift of $\delta=(7.428-$ 
$7.372 \mathrm{ppm})(\mathrm{t}, 1 \mathrm{H})$ and $\delta=(6.980-6.950 \mathrm{ppm})(\mathrm{d}, 1 \mathrm{H})$ respectively. The splitting pattern, chemical shift and $\mathrm{J}$ coupling of protons are shown in Table 1.

Table 1: The splitting pattern, chemical shift and J coupling of protons.

\begin{tabular}{lccc}
\hline Protons & Chemical shifts (ppm) & Splitting pattern & $\mathrm{J}(\mathrm{Hz})$ \\
\hline H3, H4 & $7.282-7.237$ & Unequal multiplet $(2 \mathrm{H})$ & - \\
H1 & $7.428-7.372$ & $\operatorname{triplet}(1 \mathrm{H})$ & 4.5 \\
H6 & 12.983 & $\operatorname{singlet}(1 \mathrm{H})$ & - \\
H7 & 9.140 & $\operatorname{singlet}(1 \mathrm{H})$ & - \\
H8 & 8.624 & $\operatorname{singlet}(1 \mathrm{H})$ & - \\
H2 & $8.262-8.246$ & $\operatorname{doublet}(1 \mathrm{H})$ & 5.0 \\
H10 & $6.980-6.580$ & $\operatorname{doublet}(1 \mathrm{H})$ & 7.5 \\
H11 & $7.534-7.510$ & $\operatorname{doublet}(1 \mathrm{H})$ & 3.5 \\
H5 & 2.514 & $\operatorname{singlet}(3 \mathrm{H})$ & - \\
H9 & 2.369 & $\operatorname{singlet}(3 \mathrm{H})$ & - \\
\hline
\end{tabular}

Figure 5 shows the ${ }^{13} \mathrm{C}$ NMR spectrum of 2-methyl-N-((4-methylpyridin-2yl)carbamothioyl)benzamide. Acetone was used as the deuterated solvent at the chemical shift of 30.06 and $206.33 \mathrm{ppm}$. The most de-shielded ${ }^{13} \mathrm{C}$ NMR signals correspond to $\mathrm{C}=\mathrm{O}$ and $\mathrm{C}=\mathrm{S}$ groups. The carbon atom of thiocarbonyl group $\delta 178.54 \mathrm{ppm}$ shows the highest values, due to the lower excitation energy $n-\Pi^{*}{ }^{21}$ The ${ }^{13} \mathrm{C}$ NMR signals of carbonyl group appearing at $\Pi 171.29 \mathrm{ppm}$ are more deshielded in the NMR spectra, due to the existence of the intra-molecular hydrogen bond related to the carbonyl oxygen atom. Meanwhile, the aromatic carbon resonance can be found in between $\delta \mathrm{c} 116.79-152.73 \mathrm{ppm}$ which is corresponding to the benzene rings and pyridine ring in the compound. The methyl $\left(\mathrm{CH}_{3}\right)(\mathrm{C} 5$ and $\mathrm{C} 13)$ group attached to the benzene ring and pyridine ring could be determine at the most upfield region which is $\delta c 19.97$ and 21.41 and ppm respectively. Otherwise, the summarisation of the chemical shift of the carbon for this compound was shown in Table 2. 


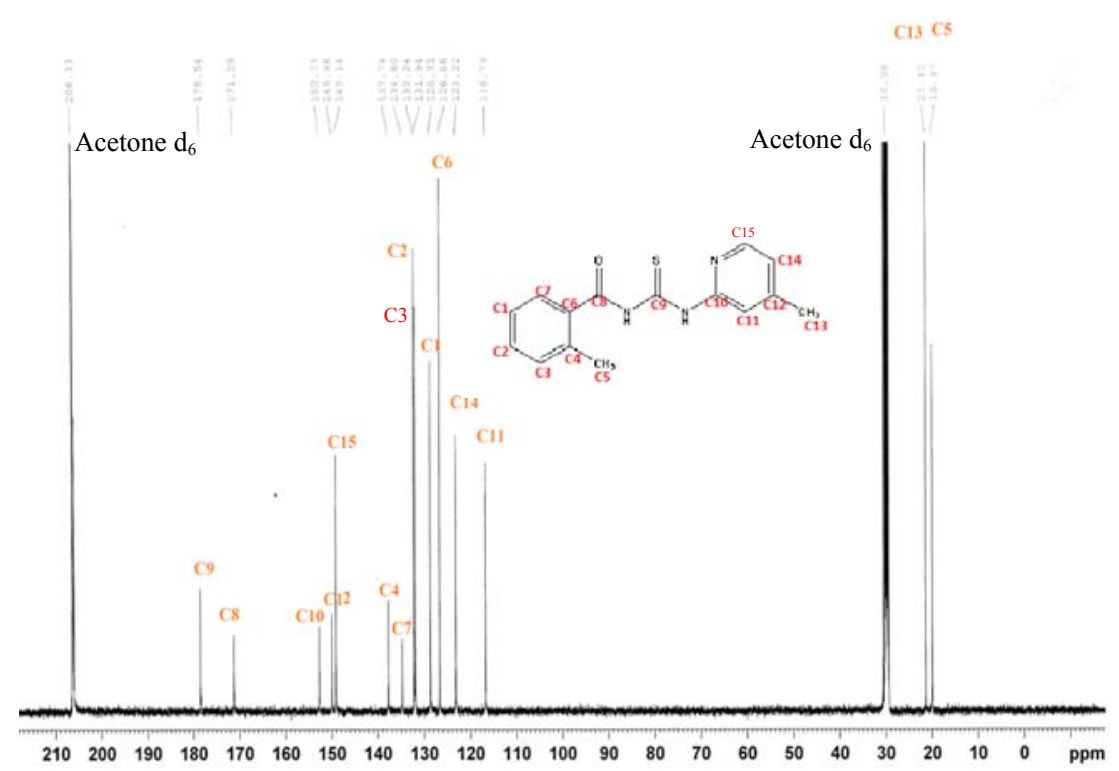

Figure $5:{ }^{13} \mathrm{C}$ NMR for 2-methyl-N-((4-methylpyridin-2-yl)carbamothioyl)benzamide.

Table 2: The chemical shift of the carbon.

\begin{tabular}{cc}
\hline Carbon & Chemical shift $(\mathrm{ppm})$ \\
\hline $\mathrm{C} 1$ & 128.72 \\
$\mathrm{C} 2$ & 132.24 \\
$\mathrm{C} 3$ & 134.80 \\
$\mathrm{C} 4$ & 137.74 \\
$\mathrm{C} 5$ & 19.97 \\
$\mathrm{C} 6$ & 126.66 \\
$\mathrm{C} 7$ & 134.80 \\
$\mathrm{C} 8$ & 171.29 \\
$\mathrm{C} 9$ & 178.54 \\
$\mathrm{C} 10$ & 152.74 \\
$\mathrm{C} 11$ & 116.79 \\
$\mathrm{C} 12$ & 149.14 \\
$\mathrm{C} 13$ & 21.41 \\
$\mathrm{C} 14$ & 123.22 \\
$\mathrm{C} 15$ & 149.14 \\
\hline
\end{tabular}




\subsection{X-ray Crystallographic Analysis}

The crystal data were collected using $\mathrm{x}-2 \mathrm{~h}$ scan techniques on an Agilent SuperNova (single source at offset and Eos CCD detec-tor) diffractometer with SuperNova (Mo) X-ray Source (Mo-Ka, $\mathrm{k}=0.71073 \AA$ ). The CrysAlisPro software program was used for data collection, cell refinement and data reduction. Using Olex2, the structure was solved by ShelS ${ }^{22}$ structure solution program using direct methods and refined with the ShelXL ${ }^{23}$ refinement package using least squares minimisation. To prepare material for publication Mercury 3.0 were used. All $\mathrm{H}$ atoms were refined using a riding model.

The structure of 2-methyl-N-((4-methylpyridin-2-yl)carbamothioyl)benzamide was confirmed by the result of a single crystal X-ray structure determination as shown in the Figure 6. Experimental details for data collection and structure refinement are summarised in Table 3 while Table 4 shows the intra and inter molecular interactions.

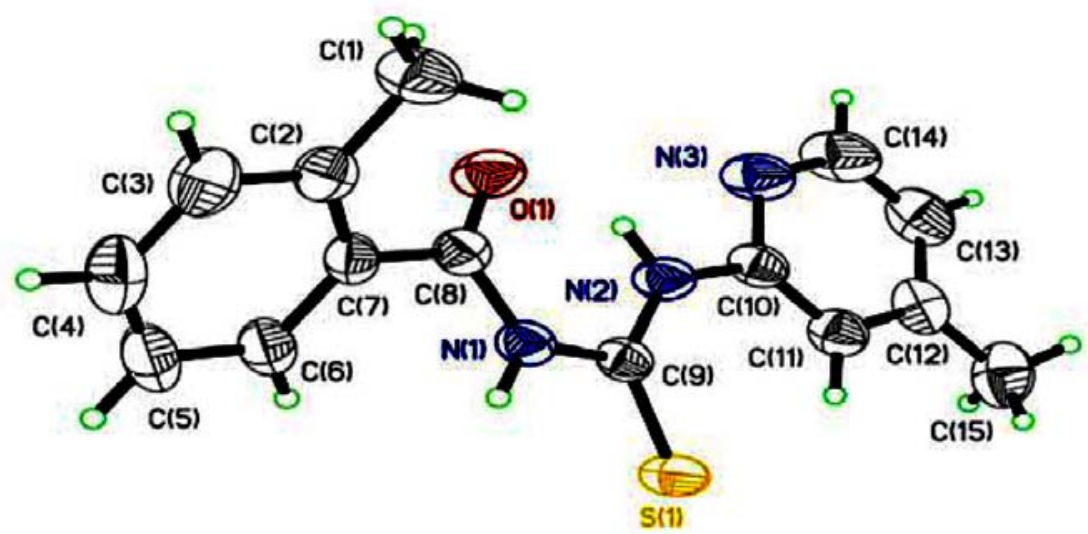

Figure 6: X-ray analysis of 2-methyl-N-((4-methylpyridin-2-1)carbamothioyl)benzamide. 
Table 3: Crystal data, data collection and structure refinement parameters of 2-methyl$\mathrm{N}$-((4-methylpyridin-2-yl)carbamothioyl)benzamide.

\begin{tabular}{|c|c|}
\hline Complex & $\begin{array}{l}\text { 2-methyl-N-((4-methylpyridin-2-yl) } \\
\text { carbamothioyl)benzamide (1) }\end{array}$ \\
\hline Chemical formula & $\mathrm{C}_{15} \mathrm{H}_{15} \mathrm{~N}_{3} \mathrm{OS}$ \\
\hline Formula weight & 285.36 \\
\hline Temperature & $100(2) \mathrm{K}$ \\
\hline Wavelength & $0.71073 \AA$ \\
\hline Crystal size & $0.090 \times 0.120 \times 0.250 \mathrm{~mm}$ \\
\hline Crystal system & monoclinic \\
\hline Space group & P $121 / \mathrm{c} 1$ \\
\hline \multicolumn{2}{|l|}{ Unit cell dimensions: } \\
\hline $\mathrm{a}=11.730(2) \AA$ & $\alpha=90^{\circ}$ \\
\hline $\mathrm{b}=6.2343(12) \AA$ & $\beta=95.361(4)^{\circ}$ \\
\hline$c=19.527(4) \AA$ & $\gamma=90^{\circ}$ \\
\hline Density (calculated) & $1.333 \mathrm{~g} \mathrm{~cm}^{-3}$ \\
\hline Volume & $1421.7(5) \AA^{3}$ \\
\hline $\mathrm{Z}$ & 4 \\
\hline Absorption coefficient & $0.227 \mathrm{~mm}^{-1}$ \\
\hline $\mathrm{F}(000)$ & 600 \\
\hline Theta range for data collection & 2.10 to $28.77^{\circ}$ \\
\hline Goodness-of-fit on $\mathrm{F}^{2}$ & 1.039 \\
\hline$\Delta / \sigma_{\max }$ & 0.001 \\
\hline \multicolumn{2}{|l|}{ Final R indices: } \\
\hline 3083 data; $\mathrm{I}>2 \sigma(\mathrm{I})$ & $\mathrm{R} 1=0.0342, \mathrm{wR} 2=0.0861$ \\
\hline all data & $\mathrm{R} 1=0.0441, \mathrm{wR} 2=0.0912$ \\
\hline
\end{tabular}


Table 4: Hydrogen bonding distances and angles of 2-methyl-N-((4-methylpyridin 2yl)carbamothioyl)benzamide (1).

\begin{tabular}{ccccc}
\hline D-H $\cdots$ A distance $(\AA)$ & $\begin{array}{c}\mathrm{D}-\mathrm{H} \cdots \mathrm{A} \\
\text { distance }(\AA)\end{array}$ & $\begin{array}{c}\mathrm{D}-\mathrm{H} \cdots \mathrm{A} \\
\text { distance }(\AA)\end{array}$ & $\begin{array}{c}\mathrm{D}-\mathrm{H} \cdots \mathrm{A} \\
\text { distance }(\AA)\end{array}$ & $\begin{array}{c}\mathrm{D}-\mathrm{H} \cdots \mathrm{A} \\
\text { distance }(\AA)\end{array}$ \\
\hline $\mathrm{C} 11-\mathrm{H} 11 \ldots \mathrm{S} 1$ & 0.95 & 2.54 & $3.2051(13)$ & 127.5 \\
$\mathrm{~N} 1-\mathrm{H} 1 \ldots \mathrm{S} 1$ & 0.88 & 2.58 & $3.4038(12)$ & 156.1 \\
$\mathrm{~N} 2-\mathrm{H} 2 \ldots \mathrm{O} 1$ & 0.88 & 1.89 & $2.6372(14)$ & 142.2 \\
\hline
\end{tabular}

$D=$ Donor atom, $A=$ Acceptor Atom

In 2-methyl-N-((4-methylpyridin-2-yl)carbamothioyl)benzamide the bond lengths and angles are generally normal in the N-alkyl-N-benzoylthiourea compounds. The structure of 2-methyl-N-((4-methylpyridin 2yl)carbamothioyl) benzamide) as shown in Figure 7 was confirmed by the result of a single crystal $\mathrm{X}$-ray structure determination. It adopted a monoclinic structure. There are two types of bonding exist in the compound, which is intramolecular and intermolecular hydrogen bond. The selected bond length and angles are presented in Table 5.

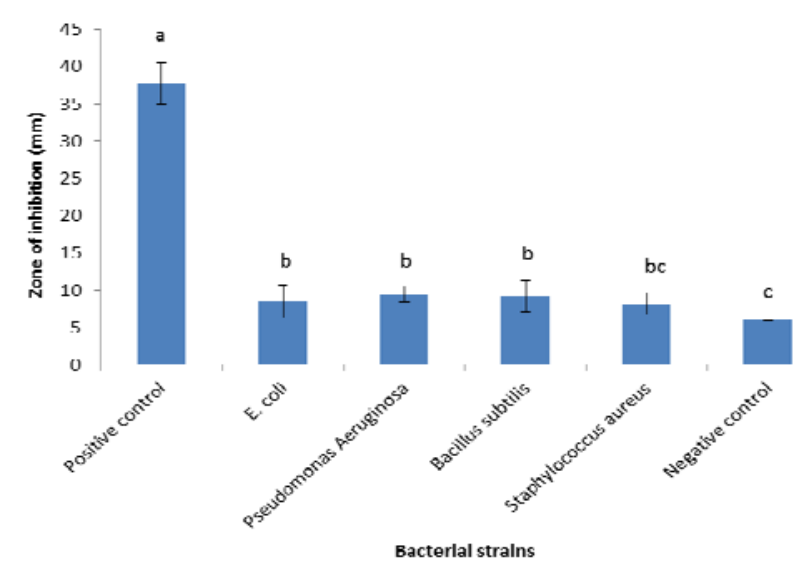

Figure 7: Inhibition zone value for each bacterium strain. 
Table 5: Selected bond lengths $(\AA)$ and bond angles $\left({ }^{\circ}\right)$ of 2-methyl-N-((4methylpyridine-2yl) carbamothioyl) benzamide.

\begin{tabular}{ll}
\hline Bond lengths & \multicolumn{1}{c}{$(\AA)$} \\
\hline C7-C8 & $1.4944(17)$ \\
C8-N1 & $1.3930(16)$ \\
C9-N1 & $1.3915(16)$ \\
C10-N3 & $1.3411(16)$ \\
C10-N2 & $1.4157(16)$ \\
C11-H11 & 0.95 \\
N1-H1 & 0.88 \\
C8-O1 & $1.2229(15)$ \\
C9-N2 & $1.3392(15)$ \\
C9-S1 & $1.6755(13)$ \\
C10-C11 & $1.3929(18)$ \\
C14-N3 & $1.3383(18)$ \\
N2-H2 & 0.88 \\
\hline Bond angles & \multicolumn{1}{|c}{$\left({ }^{\circ}\right)$} \\
\hline N1-C8-C7 & $114.49(10)$ \\
N2-C9-S1 & $127.06(10)$ \\
N3-C10-C11 & $123.99(12)$ \\
C11-C10-N2 & $125.99(11)$ \\
C10-C11-H11 & 120.7 \\
C9-N2-C10 & $132.02(11)$ \\
N2-C9-N1 & $114.81(11)$ \\
N1-C9-S1 & $118.13(9)$ \\
N3-C10-N2 & $110.00(11)$ \\
C9-N1-C8 & $128.54(10)$ \\
\hline &
\end{tabular}

In 2-methyl-N-((4-methylpyridin-2-yl)carbamothioyl)benzamide, the bond lengths and angles are generally normal in the $\mathrm{N}$-alkyl-N'-benzoylthiourea compounds. The bond length of the carbonyl $(\mathrm{C} 8-\mathrm{O} 1=1.229(15) \AA)$ group of the compound have typical double bond character. However, the thiocarbonyl group

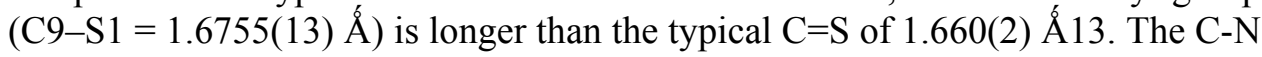
bond lengths for the investigated compound are all shorter than the average single $\mathrm{C}-\mathrm{N}$ bond length of $1.472(5)$ Á, being $\mathrm{C} 8-\mathrm{N} 1=1.3930(16) \AA$ Á, C9-N1 =

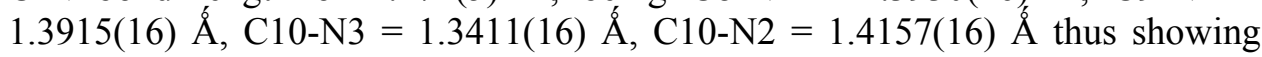
varying degrees of single bond character. 
Figure 8 shows the intramolecular and intermolecular hydrogen bonding of the compound. There are two intramolecular hydrogen bonds from C11-H11---S1 and N2-H2---O1 which have lengths of 3.2051(13) $\AA$ and 2.6372(14) $\AA$ respectively. Meanwhile, the other two intermolecular hydrogen bonds form from N1-H1---S1 with length of 3.4028(12) Á. All of them are in the range of typical hydrogen bond length between $2.6 \AA$ and $3.5 \AA$. Bond characters of the structure are presumed as a result of the intra-molecular H-bond "locking" the molecule into a pseudo-planar six-membered ring structure. These results are in agreement with the expected delocalisation in the compound and confirmed by $\mathrm{C} 9-\mathrm{N} 2-\mathrm{C} 10$ $=132.02(11)^{\circ}$ and $\mathrm{C} 9-\mathrm{N} 1-\mathrm{C} 8=128.54(10)^{\circ}$ angles showing a sp2 hybridisation on the $\mathrm{N} 1$ and $\mathrm{N} 2$ atoms as shown in Table 5.

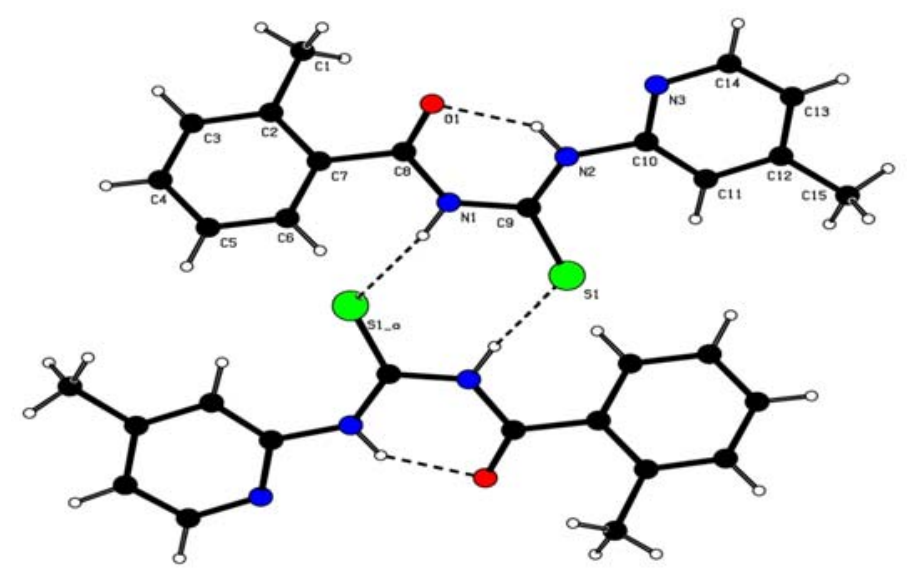

Figure 8: Hydrogen bonding of 2-methyl-N-((4-methylpyridin-2-yl) carbamothioyl) benzamide.

According to the structure, the molecule was too rigid that the $\mathrm{N}(2)-\mathrm{C}(10)$ and $\mathrm{N}(1)-\mathrm{C}(8)$ sigma bond cannot make rotations so that the $\mathrm{C}=\mathrm{O}$ and $\mathrm{C}=\mathrm{S}$ align at the same side in order for $\mathrm{O}$ and $\mathrm{S}$ atom to donate their electron simultaneously to the metal. Figure 9 shows the crystal packing of 2-methyl-N-((4-methylpyridin-2yl)carbamothioyl)benzamide viewed along $b$-axis in one unit cell. 


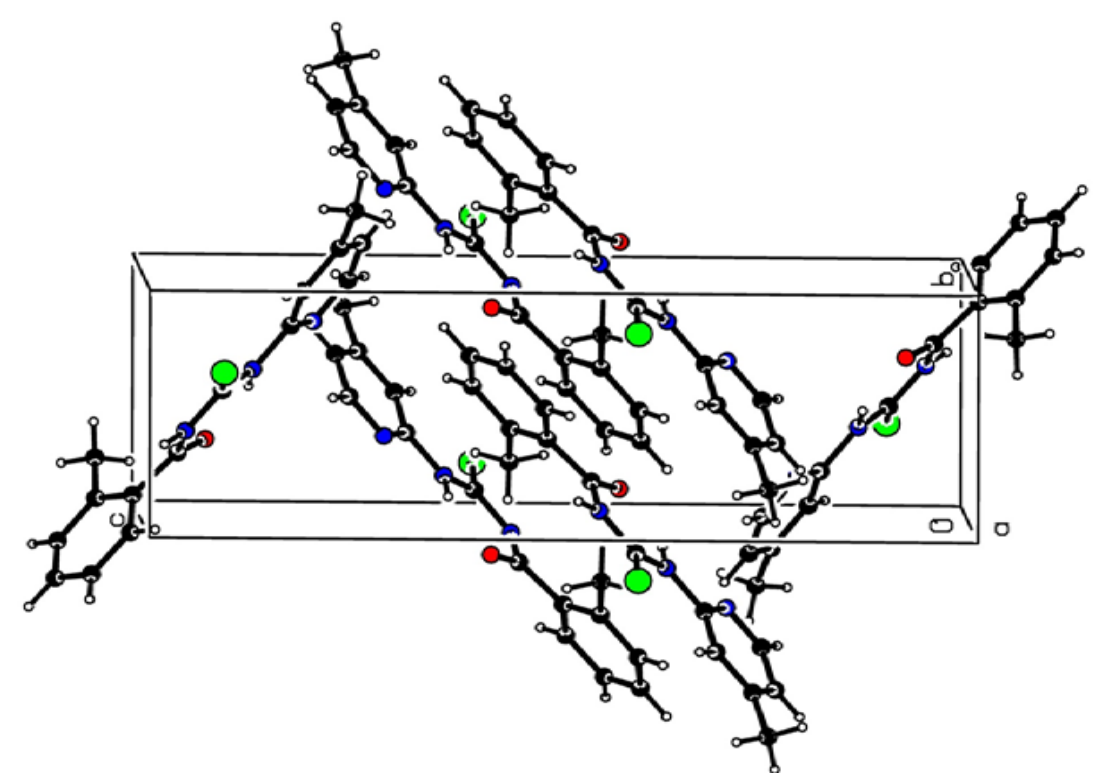

Figure 9: Packing diagram of 2-methyl-N-((4-methylpyridin-2-yl) carbamothioyl) benzamide.

The crystal structure was deposited at the Cambridge Crystallographic Data Centre. The data have been assigned the following deposition numbers: CCDC 974439.

\subsection{Antimicrobial Test}

Four pathogenic strains namely Escherichia coli ATCC 25922, Pseudomonas aeruginosa ATCC 27853, Staphylococcus aureus ATCC 25923 and one generally regarded as safe (GRAS) bacteria Bacillus subtilis were used in this study. Escherichia coli ATCC 25922 are rod shaped gram-negative bacteria that causes diarrheal illness worldwide, with over 2 million deaths taking place each year. ${ }^{24}$ Pseudomonas aeruginosa ATCC 27853 a gram-negative rod is the most common pathogen that causes acute respiratory infections in ventilated or immunocompromised humans and chronic respiratory infections in cystic fibrosis patients. ${ }^{25,26}$ Gram-positive bacteria Staphylococcus aureus ATCC 25923 is a facultative anaerob and the staphylococcal infections remains partly understood. ${ }^{27}$ Bacillus subtilis is a gram-positive bacterium and has been granted the generally recognised as safe (GRAS) status. ${ }^{28}$

The susceptibility of bacteria to the tested compound was evaluated by the formation of zone of inhibition after $18 \mathrm{~h}$ of incubation at $36^{\circ} \mathrm{C}$. Each set of experiment was done in six replicates. Figure 7 reports the inhibition zones of 
each bacteria strain against the compound. The inhibition zones ranged from 8 $\mathrm{mm}, 9 \mathrm{~mm}, 10 \mathrm{~mm}$ and $8 \mathrm{~mm}$ for E. coli ATCC 25922, Pseudomonas Aeruginosa ATCC 27853, Bacillus Subtilis and Staphylococcus Aureus ATCC 25923 respectively. The difference between gram-negative and gram-positive bacteria is due to cell wall peptidoglycan layer. ${ }^{29}$ Gram positive bacteria have a thicker peptidoglycan layer compared to gram negative bacteria. ${ }^{30}$ In this study, although gram positive bacteria were more resistant, the compound could still penetrate and resulting in inhibition zones. From the overall results, antibacterial activity of this compound show mild activity $(8$ to $10 \mathrm{~mm})$ and indicate that this compound has antimicrobial properties and has a potential as an antibacterial agent.

\section{CONCLUSION}

A thiourea benzamide derivative, 2-methyl-N-((4-methylpyridin-2$\mathrm{yl}$ )carbamothioyl)benzamide with electronegative atom, $\mathrm{S}$ and $\mathrm{O}$ in transconfiguration has been successfully synthesised with moderate yield. The chemical structures elucidated by $\mathrm{CHN}$ elemental analysis, single crystal X-ray analysis, FTIR, ${ }^{1} \mathrm{H}$ NMR, ${ }^{13} \mathrm{C}$ NMR and UV-visible spectroscopy proved the expected compound. The mechanism for the formation of the compound consists of two parts. The first part was the nucleophilic attack of partially positive carbonyl carbon by thiocyanate group forming isothiocyanate. The leaving chloride ion formed ammonium chloride. In the second part, the carbon of isothiocyanate was then attacked by the electron pair of nitrogen atom. It then underwent proton transfer to form 2-methyl-N-((4-methylpyridine-2yl)carbamothiol)benzamide. Thus, this result can be used as fundamental information in creating antibacterial medicines. Further analysis can be carried out to determine the minimum inhibitory concentration (MIC) value in future studies.

\section{ACKNOWLEDGEMENT}

The authors would like to thank Universiti Sains Malaysia for the Research University (RU) research grant (1001/PKIMIA/ 811269) which partly supported this work. 


\section{REFERENCES}

1. Cauzzi, D. et al. (2000). Pd(II) and $\mathrm{Rh}(\mathrm{I})$ chelate complexes of the bidentate phosphino-thiourea ligand $\mathrm{PhNHC}(\mathrm{S}) \mathrm{NHCH} 2 \mathrm{CH} 2 \mathrm{PPh} 2$ : Structural properties and activity in homogeneous and hybrid catalysis. $J$. Organometal. Chem., 593(1), 431-444, DOI: 10.1016/S0022328X(99)00615-4.

2. Bai, J. et al. (2010). Chiral primary amine thiourea promoted highly enantioselective Michael reactions of isobutylaldehyde with maleimides. Tetrahedr., 66, 8928-8932, DOI: 10.1016/j.tet.2010.09.044.

3. Li, S. et al. (2012). Synthesis and fungicidal activity of new fluorinecontaining mandelic acid amide compounds. J. Fluorine Chem., 133, 120-126, DOI: 10.1016/j.jfluchem.2012.02.011.

4. Mei, R. Q. et al. (2011). Highly effective and enantioselective Michael addition of 4-hydroxycoumarin to alpha,beta-unsaturated ketones promoted by simple chiral primary amine thiourea bifunctional catalysts. Tetrahedr. Lett., 52, 1566-1568.

5. Herrera, R. P. et al. (2011). Catalytic enantioselective Friedel-Crafts alkylation of indoles with nitroalkenes by using a simple thiourea organocatayst. Angewandte Chem. Int., 44(40), 6576-6579. DOI: 10.1002/anie.200500227.

6. Hidayah, R. (2007). Synthesis of a few New 3-phenylpropionylthiourea Derivatives. MSc diss., Universiti Malaysia Terengganu, Malaysia.

7. Wagner, P., Baltro, S. N. \& Kubicki, M. (2003). N-benzoylthiourea. Acta Crystallogr. C., 59, 83-84.

8. Wozniak, K., Wawer, I. \& Strohl, D. (1995). Structural similarities and differences between N-phenylureas and N-phenylthioureas. J. Phys. Chem., 99, 8888-8895, DOI: 10.1021/j100021a065.

9. Yusof, M. S. M., Yamin, B. M. \& Tajuddin, N. A. (2006). 1-(3methylbenzoyl)-3-(6-methyl-2-pyridyl)thiourea. Acta Crystallogr., 62, 3242-3244, DOI: 10.1107/S1600536806025414/bh2029Isup2.hkl.

10. Vivas-Reyes, R. et al. (2008). Theoretical study a series of N-(N-propyl)$\mathrm{N}$-(para-R-benzoyl)-thioureas with trans [pt(py)2Cl2] through chemistry reactivity descriptors based on density functional theory. J. Mol. Struct., 862, 92-97.

11. Ozer, C. K. et al. (2009) Synthesis and characterization of Nalky(aryl)carbamothioyl) cyclohexanecarboxamide derivatives and their $\mathrm{Ni}(\mathrm{II})$ and $\mathrm{Cu}(\mathrm{II})$ complexes. J. Coord. Chem., 62, 266-276.

12. Atis, M. et al. (2012). Structural, antimicrobial and computational characterization of 1-benzoyl-3-(5-chloro-2-hydroxyphenyl)thiourea. Spectrochim. Acta A, 98, 290-301, DOI: 10.1016/j.saa.2012.08.020. 
13. Allen, F. H. et al. (1987). Tables of bond lengths determined by X-ray and neutron diffraction. Part 1: Bond lengths in organic compounds. $J$. Chem. Soc. Perkin Trans., 2, S1-S19, DOI: 10.1039/p298700000s1.

14. Bernstein, J. et al. (1995). Patterns in hydrogen bonding: Functionality and graph set analysis in crystals. Angew. Chem. Int. Ed. Engl., 34, 1555-1573, DOI: 10.1002/anie.199515551.

15. Stibrany, R. et al. (1996). Synthesis, structure, and spectroscopic properties of (nitrito-O, $\left.\mathrm{O}^{\prime}\right)[\operatorname{tris}[2-(1-m e t h y l)$ imidazolyl]methoxy methane]copper(II), $\mathrm{Cu}(\mathrm{II})(\mathrm{TIMM})\left(\mathrm{NO}_{2}\right) 2(1)$. Inorg. Chim. Acta, 243, 33-37.

16. Saeed, A. \& Florke, U. (2007). (1-(2-Nitrophenyl)-3-pivaloylthiourea). Acta Cryst. E, E63, 04259. DOI: 10.1107/S1600536807063374/ at2515Isup2.hk1.

17. Emen, M. F. et al. (2005). Synthesis, characterization and antimicrobial activities of some metal complexes with $\mathrm{N}^{\prime}$-(2-chloro-benzoyl)thiourea ligands: The crystal structure of fac- [CoL3] and cis-[PdL2]. Polish $J$. Chem., 79(10), 1615-1626.

18. Douglass, I. B. et al., (1934). Some derivatives of benzoyl and furoyl isothiocyanates and their use in synthesising heterocyclic compounds. $J$. Chem. Am. Soc., 56(3), 719-721, DOI: 10.1021/ja01318a057.

19. Md. Nasir, M. F. et al. (2011). 3-(3-Methoxybenzoyl)-1,1diphenylthiourea. Acta Crystallogr. E, 67, o1947-o1948, DOI: $10.1107 / \mathrm{S} 1600536811025785$.

20. Yusof, M. S. M., Muharam, S. H., Kassim, M. B. \& Yamin, B. M. (2008). Crystal structure of N-(3-Chloropropionyl)-N $\phi-(4-$ fluorophenyl)thiourea. Acta Cryst. E, 64, o1137.

21. Yusof, M. S. M., Wong, S. T. \& Yamin, B. M. (2011). 1-(Biphenyl-4ylcarbonyl)-3-(4-nitrophenyl) thiourea. Acta Cryst. E. 67, DOI: http://dx.doi.org/10.1107/S160053681103426X.

22. Bruker. (2005). APEX2, SAINT. Bruker AXS Inc., Madison, Wisconsin, USA.

23. Bruker. (2007). SADABS. Bruker AXS Inc., Madison, Wisconsin, USA.

24. Danilo, G. M. et al. (2009). Identification of protective and broadly conserved vaccine antigens from the genome of extraintestinal pathogenic Escherichia coli. Proceed. Nat. Acad. Sci., 107(20), 90729077, DOI: 10.1073/pnas.0915077107.

25. Chastre, J. \& Trouillet, J. L. (2000). Problem pathogens (Pseudomonas aeruginosa and Acinetobacter). Semin. Respir. Infec., 15(4), 287-298, DOI: $10.1053 /$ srin.2000.20944.

26. Chastre, J. \& Fagon, J. Y. (2002). Ventilator-associated pneumonia. Am. J. Resp. Crit. Care Med., 165, 867-903, DOI: 10.1136/pgmj.2005.036905. 
27. Rachel, J. G. \& Franklin, D. L. (2008). Pathogenesis of methicillinresistant Staphylococcus aureus infection. Clin. Infect. Dis., 46(Supp. 5), 350-359, DOI 10.1086/533591.

28. Cladera-Olivera, F., Caron, G. R. \& Brandelli, A. (2004). Bacteriocinlike substance production by Bacillus licheniformis strain P40. Lett. Appl. Microbiol., 38(4): 251-256, DOI: 10.1111/j.1472-765X.2004. 01478.x.

29. Cock, I. E. (2008). Antibacterial activity of selected Australian native plant extracts. Int. J. Microbiol., 4(2), 1-8.

30. Lebleu, N. et al. (2009). Role of the cell-wall structure in the retention of bacteria by microfiltration membranes. J. Membrane Sci., 326, 178-185, DOI: 10.1016/j.memsci.2008.09.049. 